\title{
Expression of ADAMTS-1, ADAMTS-4, ADAMTS-5 and TIMP3 by hepatocellular carcinoma cell lines
}

\author{
SHARON L. TURNER ${ }^{1}$, DAVID MANGNALL ${ }^{2}$, NIGEL C. BIRD ${ }^{2}$, \\ ROWENA A.D. BUNNING ${ }^{1}$ and MARIA E. BLAIR-ZAJDEL ${ }^{1}$ \\ ${ }^{1}$ Biomedical Research Centre, Sheffield Hallam University, Sheffield, S1 1WB; \\ ${ }^{2}$ Liver Research Group, Royal Hallamshire Hospital, University of Sheffield, Sheffield, S10 2JF, UK
}

Received March 2, 2012; Accepted April 24, 2012

DOI: 10.3892/ijo.2012.1525

\begin{abstract}
Little is known about the expression or role of ADAMTS-1, -4 and -5 and their endogenous inhibitor TIMP3 in the liver in physiological and pathological conditions. Their expression was, therefore, investigated in the hepatocellular carcinoma cell lines HepG2 and HuH-7 using qRT-PCR and western blotting, and their cellular localisation by immunocytochemistry. Cytokine treatments were used to assess mRNA and protein modulation. ADAMTS-1, $-4,-5$ and TIMP3 mRNA and protein were detected in both HepG2 and HuH-7 cells. IL-1 $\beta$ and IL- 6 treatments significantly modulated ADAMTS-1 mRNA expression and IL- $1 \beta$ treatment ADAMTS- 4 mRNA expression in HepG2 cells. Modulations of mRNA by $\geq 5$-fold did not translate to increased protein expression. This study showed that ADAMTS-1, -4, -5 and TIMP3 were expressed at differential levels in hepatocellular carcinoma cell lines. The pro-inflammatory cytokines IL- $1 \beta$, TNF- $\alpha$ or IL- 6 induced changes in mRNA expression, although these did not translate to the protein level.
\end{abstract}

\section{Introduction}

Hepatocellular carcinoma (HCC) is the most common primary malignant tumour occurring in the liver which accounts for $80-90 \%$ of all primary liver cancers (1). In many cases, the neoplastic transformation of hepatocytes results from accumulation of genetic changes during enhanced cell proliferation in the injured liver in response to paracrine growth factor and cytokine stimulation (2). HCCs have a considerable capacity for vascular invasion, with metastasis and recurrence being the major factors associated with the poor prognosis of HCC (3).

Correspondence to: Dr Rowena A.D. Bunning, Biomedical Research Centre, Sheffield Hallam University, Howard Street, Sheffield, S1 1WB, UK

E-mail: r.a.bunning@shu.ac.uk

Key words: a disintegrin and metalloproteinase with thrombospondin motifs (ADAMTS) $-1,-4,-5$, tissue inhibitors of metalloproteases 3 , cytokines, liver cancer
Proteolytic modification of cell surface proteins and extracellular matrix (ECM) plays a pivotal role in cancer development and metastasis. Proteolytic enzymes are involved in several processes, at the cellular and organism level, which are dysregulated in cancer, e.g. cell adhesion and migration, cell invasion and angiogenesis. In particular, they mediate tumour invasion at several stages, e.g. detachment of cells from the primary tumour, crossing vessel walls and extravasation into target organs. This involves attachment of oncogenically transformed cells to the ECM followed by its degradation and movement of invading cells through the damaged ECM $(4,5)$.

Expression and activity of several classes of proteolytic enzymes have been shown to be modified in cancer, including recently discovered a disintegrin and metalloproteinase with thrombospondin motifs (ADAMTSs). There are 19 ADAMTSs which can be involved in pathological processes such as ECM breakdown and angiogenesis (6). They consist of several domains: the prodomain, metalloproteinase domain, disintegrin-like domain, cysteine-rich domain, thrombospondin type-I repeats (TSRs) and a spacer domain. Several ADAMTSs also contain an additional unique domain(s). They are synthesised as zymogens and after proteolytic processing at the $\mathrm{N}$-terminus to remove the signal sequence and prodomain, they are secreted from cells. For most ADAMTSs this is an important step in their activation. ADAMTSs may also undergo C-terminal processing post-translationally, which can alter their localisation and substrate specificity (7).

ADAMTS-1, -4 and -5 possess the ability to cleave members of the hyalectan or lectican family of large aggregating proteoglycans (PGs), including aggrecan, versican, and brevican (8), and are therefore known as hyalectanases.

Until recently proteinases were considered to enhance tumoural angiogenesis. However ADAMTS-1, -4 and -5 have recently been shown to also have, at least in a certain context, anti-angiogenic properties (9-11). The anti-angiogenic activity of ADAMTS-1 has been mapped to the three TSRs in the C-terminus of this protein; however the spacer domain must also be present to elicit an anti-tumour response (12). The first TSR of ADAMTS-5 has also been shown to function as an angiogenesis inhibitor in vitro (5). The regions responsible for the in vitro anti-angiogenic properties of ADAMTS-4 require confirmation but are thought to include the central TSR and cysteine-rich domain (10). Conversely, ADAMTS-4 can also 
function to advance tumour progression; however its specific role has not yet been determined (13).

The proteolytic activities of ADAMTS-1, -4 and -5 are tightly regulated by the endogenous inhibitor tissue inhibitors of metalloproteases 3 (TIMP3) (14). TIMP3 is an N-glycosylated $27-\mathrm{kDa}$ protein; though an unglycosylated species of $24 \mathrm{kDa}$ has also been described. The N-terminal domain of TIMP3, as other TIMPs, provides its inhibitory action by facilitating the formation of a non-covalent binary complex (14). Interaction of TIMP3 with ECM chondroitin sulphate PGs, e.g. aggrecan, may enable TIMP3 to inhibit extracellular ADAMTS enzymes (15). The dysregulated expression of TIMP3 has been observed at various stages of cancer progression.

Cytokines can also be dysregulated in cancer, and some of these cytokines have been found to regulate the expression of TIMPs. This may provide a mechanism for controlling the proteolytic activity of enzymes under TIMP control. For example when the pro-inflammatory cytokines interleukin- $1 \beta$ (IL-1 $\beta$ ) and tumour necrosis factor- $\alpha$ (TNF- $\alpha$ ) are applied simultaneously to brain endothelial cells (ECs), TIMP3 expression is almost completely blocked (16).

Many published reports implicate, sometimes with contradicting outcomes, members of ADAMTS family in the development and progression of human tumours. It is therefore of interest to investigate whether these enzymes are involved in the development and/or progression of HCCs.

In this study, HepG2 and HuH-7 cell lines were used as an in vitro model of $\mathrm{HCC}$, to investigate the expression of ADAMTS-1, -4, -5 and TIMP3 under different experimental conditions designed to replicate the inflammatory conditions associated with HCC development and progression.

\section{Materials and methods}

Cell culture. The human HCC cell lines, HepG2 (Sigma-Aldrich, Gillingham, UK) and HuH-7 (a gift from Professor M. Harris, Leeds University, Leeds, UK), were cultured in Eagle's minimum essential medium (EMEM) or Dulbecco's modified Eagle's medium (DMEM) respectively, supplemented with $10 \%$ heat-inactivated foetal calf serum, $50 \mathrm{U} / \mathrm{ml}$ penicillin, $50 \mu \mathrm{g} / \mathrm{ml}$ streptomycin, $2 \mathrm{mM}$ L-glutamine (Gibco-BRL Invitrogen, Paisley, UK) and 1\% non-essential amino acids (HepG2 only; Sigma-Aldrich). Cells were maintained in a humidified atmosphere of $95 \% \mathrm{v} / \mathrm{v}$ air and $5 \%$ $\mathrm{v} / \mathrm{v}$ carbon dioxide at $37^{\circ} \mathrm{C}$. Cells were sub-cultured using $0.5 \%$ trypsin/0.2\% EDTA (Sigma-Aldrich).

Western blotting. Cell lysates were prepared from untreated cells using CelLytic-M supplemented with $10 \%$ protease inhibitor cocktail and 10 mM 1,10-phenanthroline (SigmaAldrich) and protein concentration was determined by bicinchoninic acid (BCA) assay (Sigma-Aldrich). Cell lysates $(6 \mu \mathrm{g} /$ lane $)$ were fractionated under reducing conditions on pre-cast $10 \%$ Bis-Tris gels (NuPage ${ }^{\circledR}$, Invitrogen) in the Laemmli system (17), and transferred onto Hybond-C Extra nitrocellulose membrane (Amersham Biosciences, Amersham, UK). Following membrane blocking for $90 \mathrm{~min}$ with $5 \%$ blocking buffer [5\% milk powder in Tris-buffered saline containing $0.05 \%$ Tween-20 (TBS-T); Sigma-Aldrich], primary antibody (Abcam Plc, Cambridge, UK) was applied overnight $\left(4^{\circ} \mathrm{C}\right)$, followed by an appropriate horseradish peroxidase (HRP)-conjugated secondary antibody (anti-rabbit from Sigma-Aldrich; anti-mouse from Dako, Glostrup, Denmark) for $2 \mathrm{~h}$. Luminography was performed using the ECL Plus Chemiluminescence kit (Amersham Biosciences), and data captured and analysed on a UVP Bio-Imager using Labworks 4 software (Ultra Violet Products, Cambridge, UK). Membranes were stripped after target protein data capture with Restore Plus Western Blot Stripping Buffer (Perbio Science, Cramlington, $\mathrm{UK})$ to allow re-probing of the membrane for the internal control protein actin. Data were then quantified using integrated optical density analysis, with normalisation against actin. The following primary and secondary antibody combinations were used: rabbit polyclonal anti-human ADAMTS-1 (1:300 in TBS-T), goat polyclonal anti-rabbit IgG-HRP (1:80,000 in $0.01 \%$ blocking buffer); rabbit polyclonal anti-human ADAMTS-4 (1:750 in TBS-T), goat polyclonal anti-rabbit IgG-HRP (1:80,000 in $0.1 \%$ blocking buffer); rabbit polyclonal anti-human ADAMTS-5 (1:1,000 in TBS-T), goat polyclonal anti-rabbit IgG-HRP (1:80,000 in $2.5 \%$ blocking buffer); mouse monoclonal anti-human TIMP3 (1:500 in TBS-T), rabbit polyclonal anti-mouse IgG-HRP (1:1,000 in 1\% blocking buffer); rabbit-polyclonal anti-human actin $(1: 1,000$ in 5\% blocking buffer), goat polyclonal anti-rabbit IgG-HRP (1:80,000 in 5\% blocking buffer). For negative controls, primary antibody was omitted.

Immunocytochemistry. For immunocytochemistry (ICC), cells were seeded into 8 -well chamber slides at $1 \times 10^{5}$ cells/well in $400 \mu \mathrm{l}$ complete culture medium for $72 \mathrm{~h}$. Cells were fixed for 10 min with either $200 \mu \mathrm{l} 4 \%$ paraformaldehyde (PFA; $4^{\circ} \mathrm{C}$ ) to visualise cell surface antigens or $200 \mu \mathrm{l}$ acetone $\left(-20^{\circ} \mathrm{C}\right)$ to visualise intracellular antigens. ADAMTS $-1,-4$ and -5 primary antibodies (detailed above) and rabbit polyclonal anti-human TIMP3 (Abcam Plc) (1:50 in DPBS) were applied overnight $\left(4^{\circ} \mathrm{C}\right)$, followed by Alexa Fluor ${ }^{\circledR} 488$ goat polyclonal antibody to rabbit $\operatorname{IgG}$ (1:500 in DPBS; Molecular Probes Invitrogen) for $1 \mathrm{~h}$ in the dark. Cells were mounted in Vectashield ${ }^{\circledR}$ mounting medium (Vector Laboratories, UK) with DAPI as a counterstain. Images were captured using a Zeiss 510 laser scanning confocal microscope with oil immersion at x630 magnification, using the LSM 510 software. For negative controls, primary antibody was omitted.

Cytokine treatment of cells. For quantitative real-time (reverse transcription)-polymerase chain reaction (qRT-PCR), cells were seeded into 24 -well plates at $1 \times 10^{5}$ cells/well in $1 \mathrm{ml}$ complete culture medium for $24 \mathrm{~h}$. Cells were treated in triplicate with 1,10 or $100 \mathrm{ng} / \mathrm{ml}$ IL-1 $\beta$, TNF- $\alpha$ (reconstituted in water) or interleukin-6 (IL-6; reconstituted in $5 \mathrm{mM}$ acetic acid; PeproTech, London, UK) in $1 \mathrm{ml}$ of serum-free medium for $24 \mathrm{~h}$. Serum-free medium was used as a control for IL-1 $\beta$ and TNF- $\alpha$ treatments and serum-free medium containing $1 \mu \mathrm{l} / \mathrm{ml} 5 \mathrm{mM}$ acetic acid for IL- 6 treatments.

For western blotting cells were seeded at $5.4 \times 10^{5}$ cells/well of a 6-well plate in $1 \mathrm{ml}$ complete culture medium for $24 \mathrm{~h}$, and then treated in $1 \mathrm{ml}$ of serum-free medium for $24 \mathrm{~h}$.

Quantitative real-time polymerase chain reaction ( $q R T-P C R)$. Total-RNA was extracted from HepG2 and HuH-7 cells using 
Tri-Reagent (Sigma-Aldrich) and quantified using a Nanodrop ND-1000 spectrophotometer (Labtech International, Ringmer, UK). cDNA was synthesised from $1 \mu \mathrm{g}$ total-RNA per $20 \mu \mathrm{l}$ reaction using the $\mathrm{iScript}^{\mathrm{TM}} \mathrm{cDNA}$ synthesis kit (Bio-Rad Laboratories, Hemel Hempstead, UK). PCR primer sequences for ADAMTS-1, -4, -5 and TIMP3 were as stated by (18). PCR primer sequences for the reference genes $\beta$-actin, HPRT1 and YHWAZ were as stated previously (19). All PCR primers were obtained from Invitrogen. Reactions were performed in duplicate with an iCycler multicolour real-time PCR detection system (Bio-Rad Laboratories) using 2X ABsolute QPCR SYBR-Green fluorescein mix (ABgene Ltd, Epsom, UK) and the thermal profile: $2 \mathrm{~min}$ at $50^{\circ} \mathrm{C}, 15 \mathrm{~min}$ at $95^{\circ} \mathrm{C}$, then 40 cycles of $15 \mathrm{sec}$ at $95^{\circ} \mathrm{C}$ and $1 \mathrm{~min}$ at $60^{\circ} \mathrm{C}$. Melt curve data were collected using the profile: $30 \mathrm{sec}$ at $95^{\circ} \mathrm{C}, 30 \mathrm{sec}$ at $50^{\circ} \mathrm{C}$, then 45 cycles of $10 \mathrm{sec}$ starting at $50^{\circ} \mathrm{C}$ with an increase of $1^{\circ} \mathrm{C}$ per cycle. Data are expressed relative to the reference genes using the Pfaffl method (20) and all treatments were compared to an appropriate control. PCR product amplification was verified by agarose gel electrophoresis using $2.5 \%$ agarose gels containing ethidium bromide; samples were run concurrently with a 25 bp DNA ladder (Promega, Southampton, UK).

Statistical analyses. Statistical Package for the Social Sciences (SPSS) was used to perform all statistical analyses. Data were normalised by logarithmic, square root or negative reciprocal transformations as necessary, prior to use of the parametric one-way analysis of variance (ANOVA) followed by Dunnett's multiple comparison test to determine differences between cytokine treated and control groups. Data are presented as mean $\pm \mathrm{SE}$ of the mean (SEM), with $\mathrm{p} \leq 0.05$ considered significant.

\section{Results}

ADAMTS-1, -4, -5 and TIMP3 protein expression. Western blot analysis of HepG2 and HuH-7 cell lysates indicated that ADAMTS-1, -4, -5 and TIMP3 proteins were present in these cell types (Fig. 1). Active ADAMTS-1 (87 kDa) was predominant in HuH-7 cells, whilst HepG2 cells had low levels of this form. C-terminal fragments of processed ADAMTS-1 or breakdown products were also evident in both cell lines as 60, 50, 48 and $42 \mathrm{kDa}$ species. Active ADAMTS-4 (64 kDa) was predominant in both cell lines, with zymogen $(110 \mathrm{kDa})$ also being detected. Again C-terminal fragments of processed ADAMTS-4 or breakdown products were evident in both cell lines as 82, 60, 53 and $49 \mathrm{kDa}$ species. HepG2 cells also had a $150 \mathrm{kDa}$ band, which may represent glycosylated or dimerised enzyme. ADAMTS-5 zymogen (120 kDa) was the major form in HepG2 and HuH-7 cells, although low levels of active ADAMTS-5 were present $(70 \mathrm{kDa})$. An additional fragment at $48 \mathrm{kDa}$ was present in HepG2 cells, but absent in HuH-7 cells. Glycosylated TIMP3 (30 kDa) was present in both cell lines.

Cellular localisation of ADAMTS-1, -4, -5 and TIMP3 proteins. The cellular localisations of ADAMTS-1, -4, -5 and TIMP3 proteins were examined by ICC in HepG2 and HuH-7 cell lines, and confirmed that each of these proteins of interest was present (Fig. 2). Phase contrast microscopy demonstrated that both well-differentiated HCC cell lines HepG2 and HuH-7 displayed an epithelial-like morphology, although obvious differences in

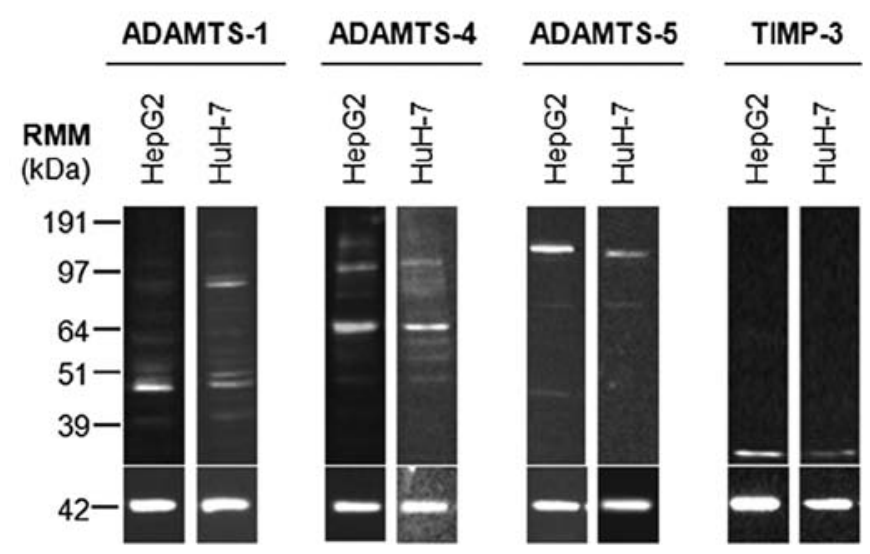

Figure 1. ADAMTS-1, ADAMTS-4, ADAMTS-5 and TIMP3 protein expression in HepG2 and $\mathrm{HuH} 7$ cell lysates. Immunoprobed western blots of SDS-PAGE fractionated HepG2 and $\mathrm{HuH} 7$ cell lysates, derived using CelLytic-M supplemented with protease inhibitors, indicated the presence of ADAMTS-1, ADAMTS-4, ADAMTS-5 and TIMP3 in both HCC cell lines. Equal loading of protein $(6 \mu \mathrm{g})$ was verified by actin immunoprobing (lower panel $42 \mathrm{kDa}$ band). Data are representative of three repeat experiments.

their growth patterns were observed (data not shown). HepG2 cells formed clusters with some areas of high confluence and others with no cells, whereas $\mathrm{HuH}-7$ cells grew as a uniform monolayer.

Each protein of interest was detected with a punctate distribution across the cell surface in both cell lines, albeit at low levels (Fig. 2A, C, E, G, I, K, M and O), whereas intracellular staining patterns varied. ADAMTS-1 was located diffusely within the cell cytoplasm with some perinuclear vesicles evident in both cell lines (Fig. 2B and D). Intracellular ADAMTS-4 showed intense cytoplasmic staining in HepG2 cells (Fig. 2F), whilst it displayed intense perimembrane staining in $\mathrm{HuH}-7$ cells (Fig. 2H). The converse was observed for ADAMTS-5 with perimembrane staining evident in HepG2 cells (Fig. 2J) and diffuse cytoplasmic staining in HuH-7 cells (Fig. 2L). Intracellular staining patterns for TIMP3 were markedly different between the cell lines examined, in HepG2 cells it was intense throughout the cytoplasm (Fig. 2N), whilst TIMP3 was diffusely distributed in the cytoplasm of $\mathrm{HuH}-7$ cells with granular perinuclear staining (Fig. 2P).

Modulation of ADAMTS-1, -4, -5 and TIMP3 by IL-1 $\beta$, TNF- $\alpha$ and IL-6 in HepG2 and HuH-7 cells. ADAMTS-1, -4 and TIMP3 mRNA were readily detected in HepG2 cells by qRT-PCR, whereas ADAMTS-5 mRNA was present only at low levels, below those required for accurate quantification (Fig. 3). Similarly ADAMTS-1 and TIMP3 mRNA were present in HuH-7 cells, but ADAMTS-4 and -5 mRNA were only detected at low levels, often below those required for accurate quantification.

qRT-PCR performed $24 \mathrm{~h}$ after IL-1 $\beta$, TNF- $\alpha$ or IL-6 treatment of $\mathrm{HuH}-7$ cells demonstrated minor modulations in ADAMTS-1, -4, -5 and TIMP3 mRNA expression, with no statistically significant modulations observed (Fig. 3). However, IL-6 treatment of HuH7 cells did increase TIMP3 mRNA expression in the range of 2.9 to 3.8 -fold, although significance was not reached due to the large SEM (Fig. 3D). Conversely, ADAMTS-1 mRNA was significantly upregu- 


\section{HepG2}
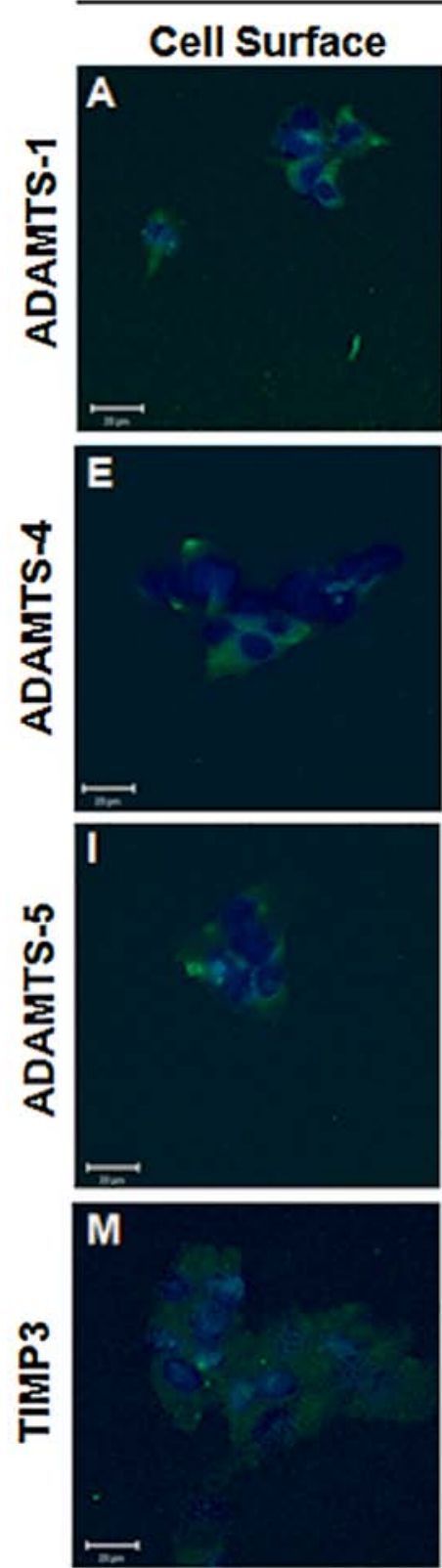
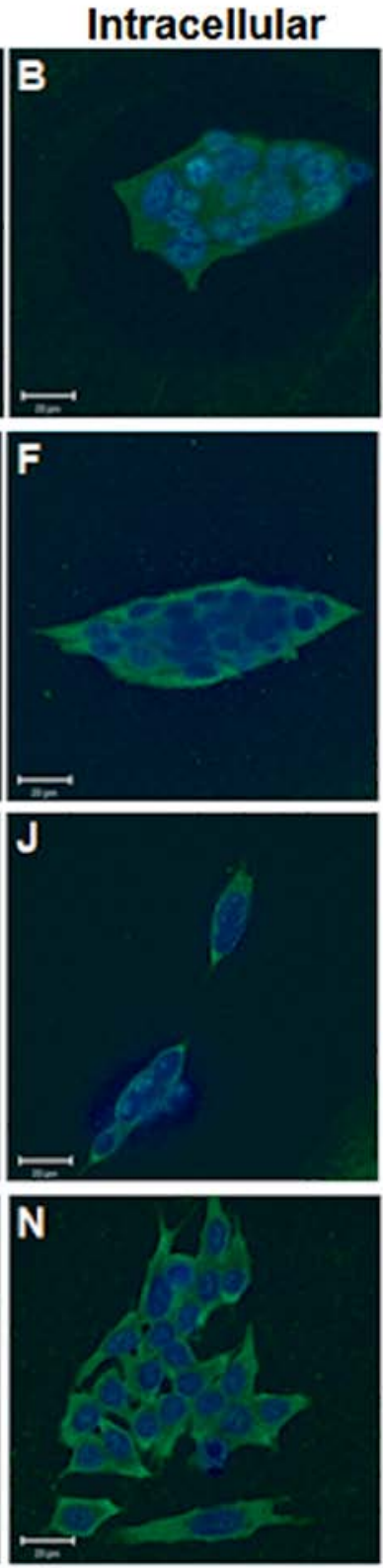

$\mathrm{HuH}-7$
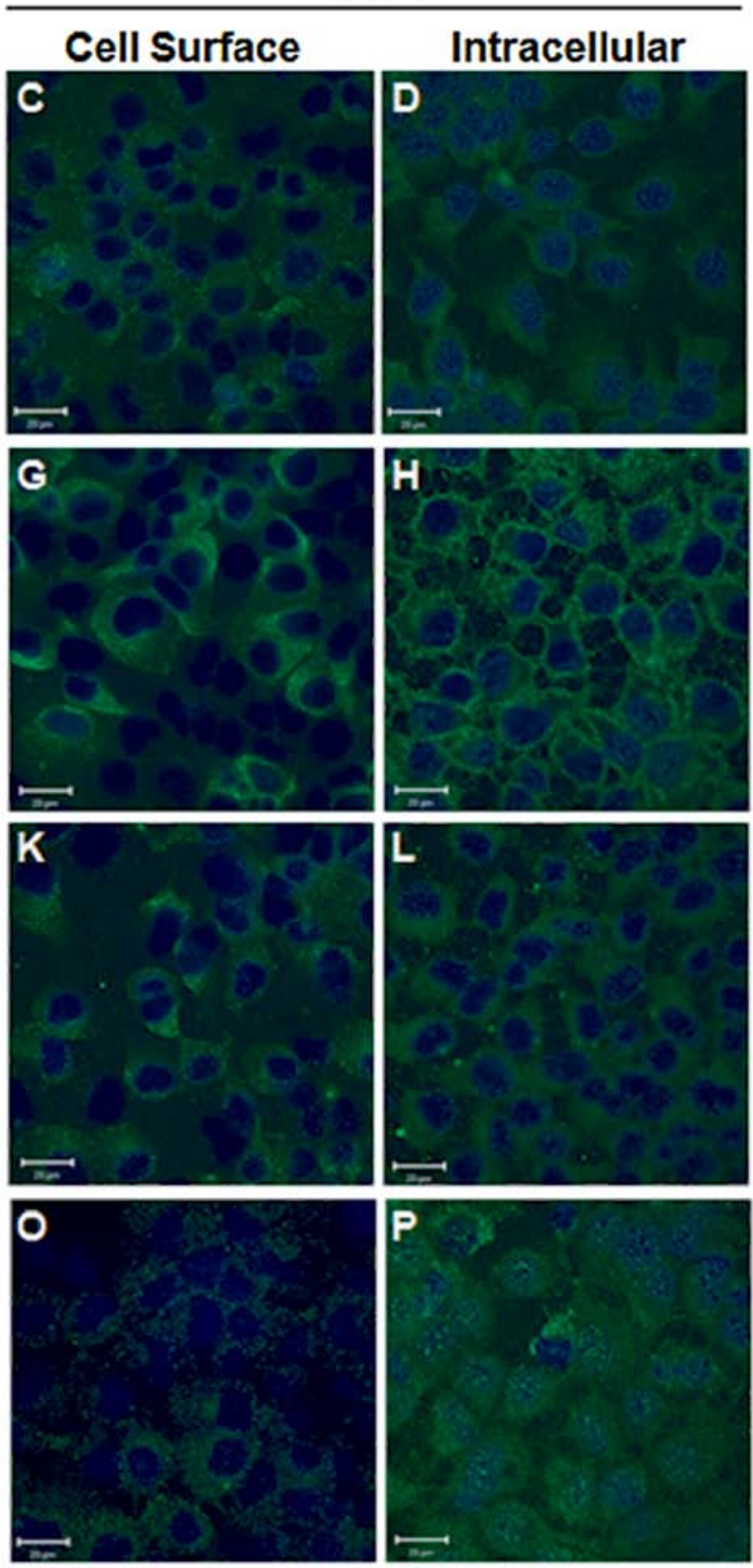

Figure 2. Immunocytochemical examination of cell surface and intracellular ADAMTS-1 (A-D), ADAMTS-4 (E-H), ADAMTS-5 (I-L) and TIMP3 (M-P) in HepG2 and HuH-7 cells. Immunocytochemistry was carried out on cells seeded into 8-well chamber slides at 1x10 $10^{5}$ cells/well in $400 \mu l$ complete culture medium for $72 \mathrm{~h}$. Cells were fixed for $10 \mathrm{~min}$ with either $4 \%$ paraformaldehyde at $4^{\circ} \mathrm{C}$, to visualise cell surface antigens, or acetone at $-20^{\circ} \mathrm{C}$, to visualise intracellular antigens Primary antibodies to ADAMTS-1, $-4,-5$ and TIMP3 were applied overnight at $4^{\circ} \mathrm{C}$, followed by Alexa Fluor ${ }^{\circledR} 488$ goat polyclonal antibody to rabbit IgG for $1 \mathrm{~h}$ in the dark. Cells were mounted in Vectashield ${ }^{\circledR}$ mounting medium with DAPI as a counter-stain and images were captured using a Zeiss 510 laser scanning confocal microscope. Scale bar, $20 \mu \mathrm{m}$. Data are representative of three repeat experiments.

lated in HepG2 following $24 \mathrm{~h}$ of 1,10 and $100 \mathrm{ng} / \mathrm{ml} \mathrm{IL-1 \beta}$ ( $p=0.002 ; p \leq 0.001 ; p \leq 0.001$, respectively) and $100 \mathrm{ng} / \mathrm{ml} \mathrm{IL-6}$ treatments $(\mathrm{p}=0.042)$ as compared to appropriate controls. ADAMTS-4 mRNA was also significantly upregulated following $24 \mathrm{~h}$ of treatment with $100 \mathrm{ng} / \mathrm{ml} \mathrm{IL-1 \beta}(\mathrm{p}=0.023)$. No significant modulations in TIMP3 mRNA were observed following cytokine treatment of HepG2 cells.

Where mRNA levels were upregulated by more than 5 -fold, western blot analysis was performed on the corresponding protein samples (Fig. 4A). HepG2 cells treated with $10 \mathrm{ng} / \mathrm{ml}$ IL-1 $\beta$ or IL- 6 did not significantly alter ADAMTS-1 protein expression, similarly $10 \mathrm{ng} / \mathrm{ml} \mathrm{TNF}-\alpha$ treatment of HepG2 cells did not significantly alter ADAMTS-4 expression, as determined by densitometry analyses (Fig. 4B). ADAMTS-1 protein expression in HepG2 cells treated with $100 \mathrm{ng} / \mathrm{ml}$ IL-6 was not examined by western blot analysis due to the large variance in ADAMTS-1 mRNA expression.

\section{Discussion}

There are many established HCC cell lines available for the in vitro study of primary liver tumours, e.g. HLE, HLF, HuH-7, 
A
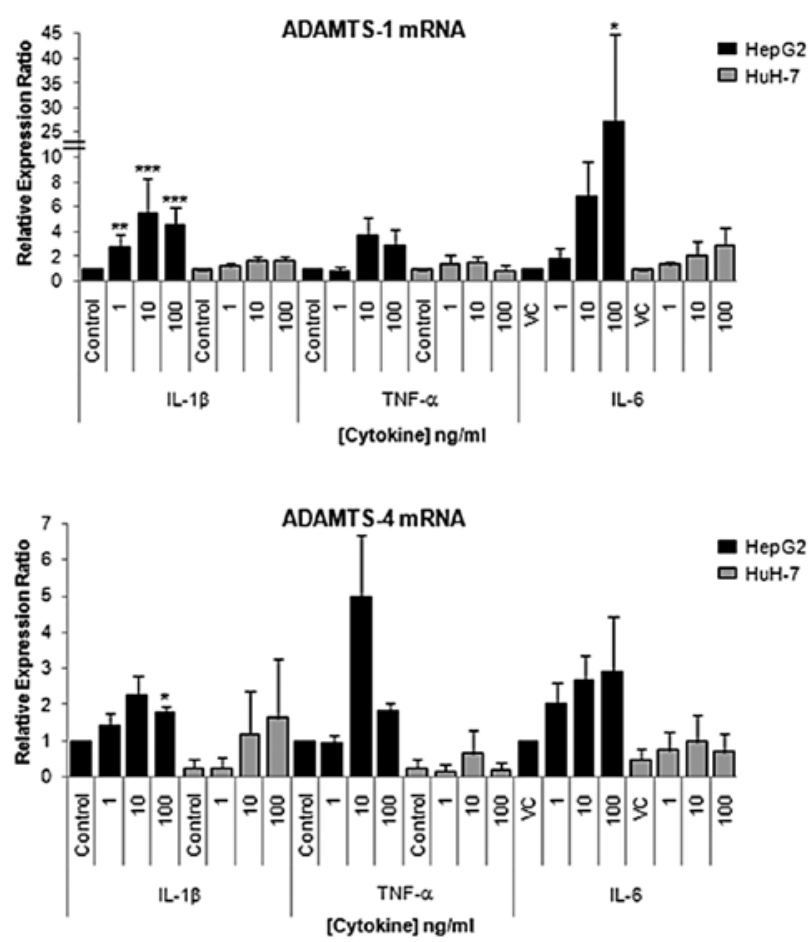

C

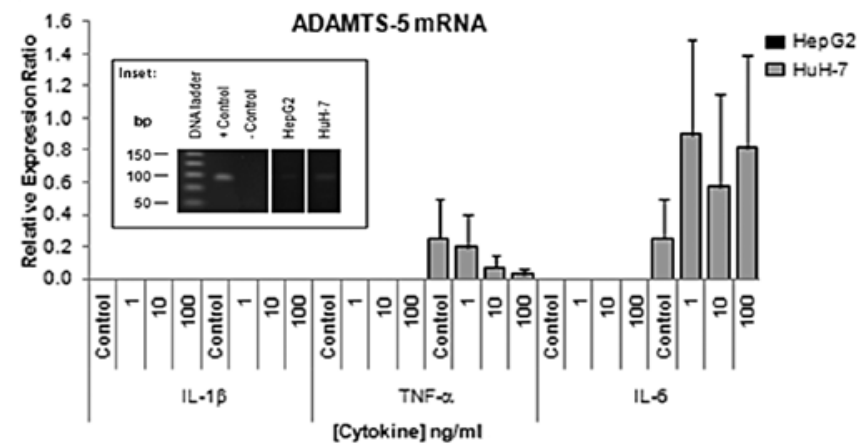

D

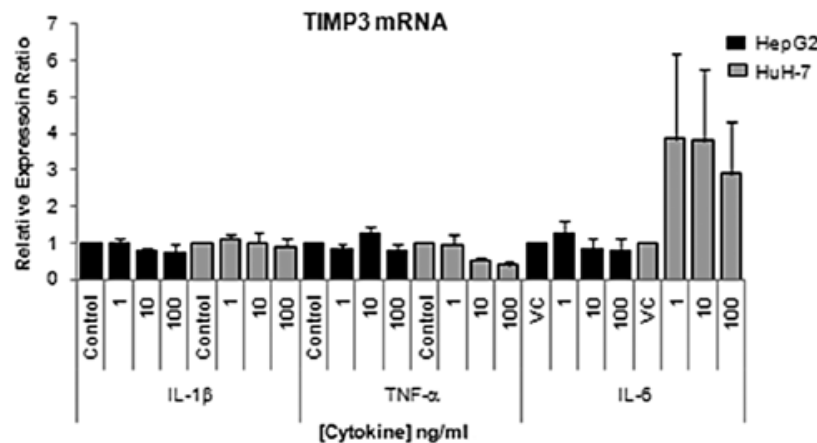

Figure 3. Expression of ADAMTS-1, $-4,-5$ and TIMP3 mRNA in HepG2 and HuH-7 cells in control cells and cells treated with pro-inflammatory cytokines. Cells, in 24-well plates, were treated with cytokines IL-1 $\beta$, TNF- $\alpha$ and IL-6 at 1, 10 or $100 \mathrm{ng} / \mathrm{ml}$ for $24 \mathrm{~h}$. Total-RNA was extracted using Tri-Reagent and reverse transcribed using the iScript $^{\mathrm{TM}}$ cDNA synthesis kit. qRT-PCR analysis is shown for (A) ADAMTS-1, (B) ADAMTS-4, (C) ADAMTS-5 and (D) TIMP3 mRNA expression in control ( $\mathrm{VC}=$ vehicle control) and cells treated with cytokines. The inset shows PCR product from positive (LX-2, human hepatic stellate cell line, cDNA) and negative controls (no template) and HepG2 and HuH-7 cDNA in HepG2 and HuH-7 cells after $24 \mathrm{~h}$. The Pffafl method was used to calculate the relative

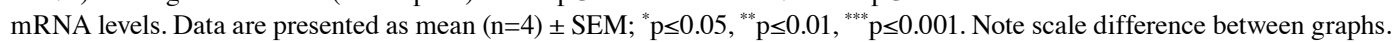

A

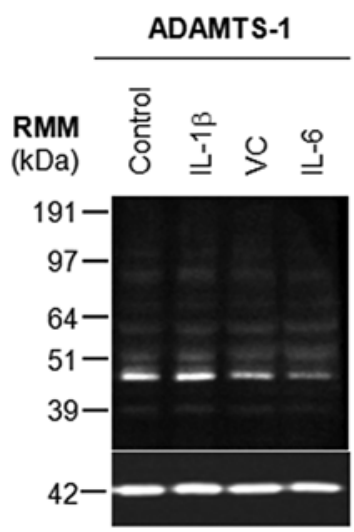

ADAMTS-4

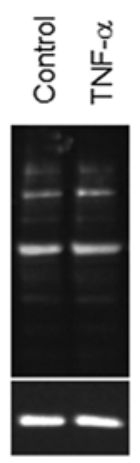

B

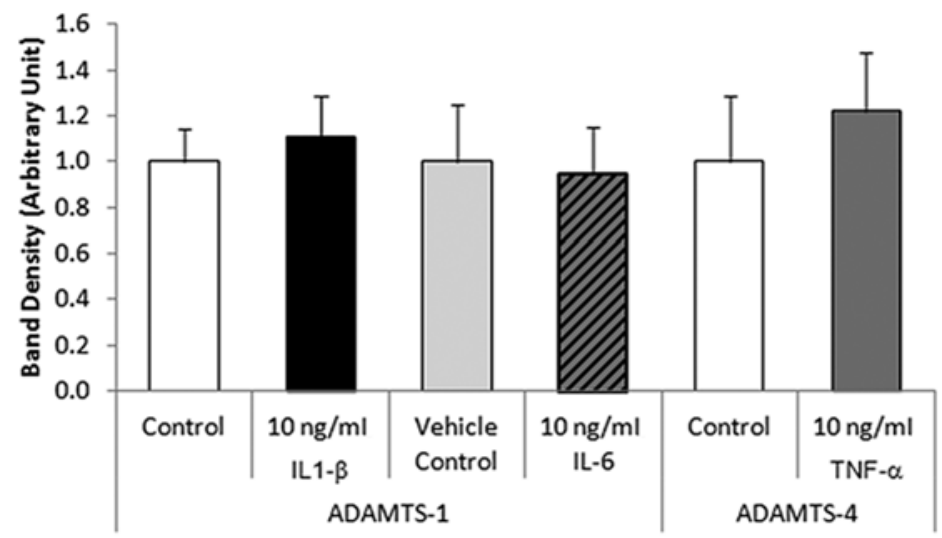

Figure 4. Cytokine modulation of ADAMTS-1 and -4 protein in HepG2 cells. HepG2 cells in 6-well plates were untreated or treated with cytokines IL-1 $\beta$ or TNF- $\alpha$ at $10 \mathrm{ng} / \mathrm{ml}$ for $24 \mathrm{~h}$. SDS-PAGE fractionated HepG2 cell lysates were analysed by western blotting (A) for ADAMTS-1 and ADAMTS-4. Equal loading of protein $(6 \mu \mathrm{g})$ was verified by actin immunoprobing (lower panel $42 \mathrm{kDa}$ band). Data are representative of three repeat experiments. (B) Shows relative quantification of total ADAMTS-1 and ADAMTS- 4 proteins after actin normalisation. Data presented as mean $(n=3) \pm$ SEM; there were no significant differences in the data.

SK-Hep1, HepG2 and Hep3B cells. Two cell lines derived from well-differentiated HCCs, HepG2 and HuH-7, were selected for use in this study, as the majority of these tumour types are surrounded by a fibrous capsule (desmoplastic reaction) (21) and require the secretion of proteolytic enzymes in order to breakdown liver ECM enabling their growth and expansion (22).

ADAMTS-1, -4 and -5 are primarily known for their ability to cleave aggrecan (23). There is also increasing evidence of 
their involvement in cancer progression with altered expression associated with both tumour promoting and inhibitory effects (6). Several mechanisms have been proposed for these effects including breakdown of ECM as well as modulation of cell proliferation and angiogenesis.

This study showed for the first time that ADAMTS-1, -4 and -5 proteins, and their major endogenous inhibitor TIMP3, are expressed in the HCC cell lines HepG2 and HuH-7.

ADAMTS-1 protein can exert both pro- and anti-angiogenic properties dependent upon its proteolytic status (24). The sequestration of vascular endothelial growth factor (VEGF)-165 by ADAMTS-1 may provide a mechanism by which this protein could mediate its anti-angiogenic activity (9). In contrast, ADAMTS-1 protein was shown to act as a positive regulator of tumoral angiogenesis and invasion when over-expressed in TA3 mammary carcinoma, Lewis lung carcinoma (24), and $\mathrm{CHO}$ cell lines (12). In this study it has been shown that ADAMTS-1 protein is expressed in both HCC cell lines examined, and both the active $(87 \mathrm{kDa})$ and $\mathrm{C}$-terminally processed forms were detected. Interestingly, the cellular localisation of ADAMTS-1 was different in these cell lines, with higher levels of cell surface-associated ADAMTS-1 in HuH-7 cells than HepG2 cells. ADAMTS-1 in this cellular compartment is thought to be in its full-length active conformation (25) where its overexpression can promote angiogenesis by the promotion of HB-EGF and amphiregulin shedding and the subsequent increase in EGFR transactivation (24). Conversely, HepG2 cells contained more intracellular ADAMTS-1-containing vesicles, thought to be secretory vesicles, possibly indicating an extra level of regulatory control over ADAMTS-1 in HepG2 cells.

A distinct role for ADAMTS-4 in cancer is yet to be elucidated; however its altered expression has been associated with cancer progression (13) and it has been suggested that the overexpression of ADAMTS-4 can increase the growth and invasive capacity of glioblastoma cells via the cleavage of brevican (26). However, more recently ADAMTS-4 has been shown to have anti-angiogenic activities in vitro including binding to VEGF and inhibiting VEGF receptor 2 phosphorylation in human dermal microvascular ECs (10).

This study demonstrates that ADAMTS-4 protein is present in HepG2 and $\mathrm{HuH}-7$ cells, and its active form (64 kDa) was mainly detected. ADAMTS-4 protein can also undergo C-terminal processing, which can affect its substrate specificity (7), and may therefore influence ECM sculpting. C-terminal processing was shown by western blot analysis, with multiple forms of this enzyme present in both HepG2 and HuH-7 cells. Levels of cell surface-associated ADAMTS-4 differed between cells both in HepG2 and HuH-7 cell lines, with some cells exhibiting very low levels of this protein which in this location is in its full-length active form (25).

ADAMTS-5 protein, like ADAMTS-1 and -4, can mediate anti-angiogenic properties, with the centrally located TSR capable of inhibiting EC tubule formation on Matrigel (11). However, it must be noted that the function of full length ADAMTS-5 in tumoural angiogenesis is currently unknown. ADAMTS-5 protein was expressed in the HCC cell lines examined predominantly as zymogen $(120 \mathrm{kDa})$, with very little active protein $(70 \mathrm{kDa})$ present. This correlated with low levels of mature ADAMTS-5 protein associated with the extracellular surface where ADAMTS-5 is in its active conformation (25).
Together these data suggest that anti-angiogenic ADAMTS-5 protein is expressed at low levels by primary HCCs which could be advantageous by allowing tumoral angiogenesis to occur.

Under normal physiological conditions TIMP3 acts to tightly regulate the proteolytic activity of a number of enzymes, including ADAMTS-1, -4 and -5 , preventing them from having pathological effects. However, the dysregulated expression of TIMPs can occur at various stages of cancer progression, with their downregulation being associated with increased tumour cell invasiveness and their over-expression providing a protective effect by reducing tumour growth, metastasis formation and angiogenesis, and inducing tumour cell apoptosis $(15,27)$.

Although TIMP3 is usually found associated with sulphated glycosaminoglycans present in the ECM $(15,28)$, it can also be associated with the cell membrane (28). This study demonstrated that very small amounts of TIMP3 were associated with the surface of each HCC cell line examined, with the majority of the protein present in the cytoplasm. This is in agreement with Miyazaki et al (29) and Darnton et al (27) who found that TIMP3 is largely cytoplasmic in many human tumours including renal carcinomas, pancreatic endocrine tumours, uveal melanomas and oesophageal adenocarcinomas. Therefore it is probable that the western blot data presented in this study largely reflects intracellular TIMP3 levels.

HCC can be described as an inflammation-associated cancer developing often in patients with chronic hepatitis and cirrhosis (30); conditions characterised by persistent liver injury, inflammation and hepatocellular proliferation (31). Therefore the elevated presence of three pro-inflammatory cytokines, IL-1 $\beta$, TNF- $\alpha$ and IL- 6 , within the liver during times of injury is unsurprising (32).

Previously, the decreased expression of ADAMTS-1 mRNA in HCCs, compared to cirrhotic liver was reported (33), but the expression of the other genes encoding proteolytic enzymes of interest have not been examined in liver tissue. Interestingly though, TIMP3 expression has been shown to be inhibited in brain ECs by the simultaneous application of IL-1 $\beta$ and TNF- $\alpha$ (16), two of the pro-inflammatory cytokines associated with liver tumour formation.

This study determined the differential expression of ADAMTS-1, -4, -5 and TIMP3 mRNAs in HepG2 and HuH-7 cells, with low levels of ADAMTS-5 mRNA in HepG 2 cells, and low levels of ADAMTS-4 and -5 mRNA in HuH-7 cells. Interestingly, comparable levels of TIMP3 gene expression were observed in both cell lines, at a higher level than the other genes examined (as determined by cycle threshold values in qRT-PCR).

These investigations further demonstrated that ADAMTS-1 mRNA expression was significantly increased by 1,10 and $100 \mathrm{ng} / \mathrm{ml}$ IL-1 $\beta$ and $100 \mathrm{ng} / \mathrm{ml}$ IL-6 in HepG2 cells ( $\leq \leq 0.002$; $\mathrm{p}=0.042$, respectively); ADAMTS -4 mRNA expression was also significantly increased by $100 \mathrm{ng} / \mathrm{ml} \mathrm{IL}-1 \beta$ in HepG 2 cells $(\mathrm{p}=0.023)$. No significant modulations in ADAMTS-1, $-4,-5$ or TIMP3 mRNA expression levels in $\mathrm{HuH}-7$ cells were detected following 24 h of IL-1 $\beta$, TNF- $\alpha$ or IL- 6 treatments. However, TIMP3 mRNA expression was downregulated following $100 \mathrm{ng} / \mathrm{ml} \mathrm{TNF}-\alpha$ treatment to a level that approached significance $(\mathrm{p}=0.055)$, whilst IL-6 treatments resulted in an approximately 4-fold upregulation of TIMP3 mRNA (significance not reached). 
Studies on protein levels revealed that there was no ADAMTS-1 protein modulation following $24 \mathrm{~h}$ of IL-1 $\beta$ or IL-6 treatment, and no ADAMTS-4 protein modulation following $24 \mathrm{~h}$ of TNF- $\alpha$ treatment, as determined by western blotting and densitometry analysis. These enzymes were selected for investigation of modulation of protein levels as considerable changes at the mRNA levels had been observed.

ADAMTS-1, -4, -5 and TIMP3 mRNA and protein were present in HepG2 and HuH-7 cells, with C-terminally processed forms of ADAMTS-1 and -4 protein evident. The pro-inflammatory cytokines, IL-1 $\beta$, TNF- $\alpha$ and IL- 6 , associated with liver tumour progression are capable of modulating their mRNA expression in vitro, although these modulations did not translate to the protein level at the time point studied. The presence of ADAMTS-1, -4 and -5 in these HCC cell lines may indicate a role in tumour development and progression as they degrade extracellular matrix large aggregating proteoglycans (23). Conversely, ADAMTS-1, -4 and -5 may inhibit angiogenesis thus inhibiting tumour growth (9-11).

\section{Acknowledgements}

Particular thanks are expressed to Dr Gail Haddock for her invaluable guidance on western blotting and confocal microscopy and to Dr Roger Jackson for his advice on statistical analyses. We also gratefully acknowledge Yorkshire Cancer Research (YCR) for partly funding this study.

\section{References}

1. Wilson JF: Liver cancer on the rise. Ann Intern Med 142: 1029-1032, 2005.

2. Merle P and Trepo C: Molecular mechanisms underlying hepatocellular carcinoma. Viruses 1: 852-872, 2009.

3. Giannelli G and Antonaci S: Novel concepts in hepatocellular carcinoma: from molecular research to clinical practice. J Clin Gastroenterol 40: 842-846, 2006.

4. Hanahan D and Weinberg RA: The hallmarks of cancer. Cell 100: 57-70, 2000.

5. Price JT and Thompson EW: Mechanisms of tumour invasion and metastasis: emerging targets for therapy. Expert Opin Ther Targets 6: 217-233, 2002.

6. Porter S, Clark IM, Kevorkian L and Edwards DR: The ADAMTS metalloproteinases. Biochem J 386: 15-27, 2005.

7. Kashiwagi M, Enghild JJ, Gendron C, Hughes C, Caterson B and Itoh Y: Altered proteolytic activities of ADAMTS-4 expressed by C-terminal processing. J Biol Chem 279: 1010910119, 2004.

8. Bandtlow CE and Zimmermann DR: Proteoglycans in the developing brain: new conceptual insights for old proteins. Physiol Rev 80: 1267-1290, 2000.

9. Luque A, Carpizo DR and Iruela-Arispe ML: ADAMTS1/ METH1 inhibits endothelial cell proliferation by direct binding and sequestration of $\mathrm{VEGF}_{165}$. J Biol Chem 278: 23656-23665, 2003.

10. Hsu Y-P, Staton CA, Cross N and Buttle DJ: Anti-angiogenic properties of ADAMTS-4 in vitro. Int J Exp Pathol 93: 70-77, 2012.

11. Sharghi-Namini S, Fan HP, Sulochana KN, Potturi P, Xiang W, Chong YS, Wang ZY, Wang H and Ge RW: The first but not the second thrombospondin type 1 repeat of ADAMTS5 functions as an angiogenesis inhibitor. Biochem Biophys Res Commun 371: 215-219, 2008.

12. Kuno K, Bannai K, Hakozaki M, Matsushima K and Hirose K: The carboxyl-terminal half region of ADAMTS-1 suppresses both tumorigenicity and experimental tumor metastatic potential. Biochem Biophys Res Commun 319: 1327-1333, 2004.
13. Held-Feindt J, Paredes EB, Blömer U, Seidenbecher C, Stark AM, Mehdorn HM and Mentlein R: Matrix-degrading proteases ADAMTS4 and ADAMTS5 (disintegrins and metalloproteinases with thrombospondin motifs 4 and 5) are expressed in human glioblastomas. Int J Cancer 118: 55-61, 2006.

14. Nagase H, Visse R and Murphy G: Structure and function of matrix metalloproteinases and TIMPs. Cardiovasc Res 69: $562-573,2006$.

15. Lambert E, Dassé E, Haye B and Petitfrère E: TIMPs as multifacial proteins. Crit Rev Oncol Hematol 49: 187-198, 2004.

16. Bugno M, Witek B, Bereta J, Bereta M, Edwards DR and Kordula T: Reprogramming of TIMP-1 and TIMP-3 expression profiles in brain microvascular endothelial cells and astrocytes in response to proinflammatory cytokines. FEBS Lett 448: 9-14, 1999.

17. Laemmli UK: Cleavage of structural proteins during the assembly of the head of bacteriophage T4: Nature 227: 680-685, 1970.

18. Haddock G, Cross AK, Plum J, Surr J, Buttle DJ, Bunning RAD and Woodroofe NM: Expression of ADAMTS-1, -4, -5 and TIMP-3 in normal and multiple sclerosis CNS white matter. Mult Scler 12: 386-396, 2006.

19. Vandesompele J, De Preter K, Pattyn F, Poppe B, Van Roy N, De Paepe A and Speleman F: Accurate normalization of real-time quantitative RT-PCR data by geometric averaging of multiple internal genes. Genome Biol 3: Research 0034, 2002.

20. Pfaffl MW: A new mathematical model for relative quantification in real-time RT-PCR. Nucleic Acids Res 29: e45, 2001.

21. Nakashima T, Okuda K, Kojiro M, Jimi A, Yamaguchi R, Sakamoto K and Ikari T: Pathology of hepatocellular carcinoma in Japan. 232 consecutive cases autopsied in ten years. Cancer 51: 863-877, 1983.

22. Illemann M, Bird NC, Majeed A, Lærum OD, Lund LR, Danø K and Nielsen BS: Two distinct expression patterns of urokinase, urokinase receptor and plasminogen activator inhibitor-1 in colon cancer liver metastases. Int J Cancer 124: 1860-1870, 2009.

23. Jones GC and Riley GP: ADAMTS proteinases: a multi-domain, multi-functional family with roles in extracellular matrix turnover and arthritis. Arthritis Res Ther 7: 160-169, 2005.

24. Liu YJ, Xu Y and Yu Q: Full-length ADAMTS-1 and ADAMTS-1 fragments display pro- and antimetastatic activity, respectively. Oncogene 25: 2452-2467, 2006.

25. Seals DF and Courtneidge SA: The ADAMs family of metalloprotease: Multidomain proteins with multiple functions. Genes Dev 17: 7-30, 2003.

26. Hu B, Kong LL, Mathews RT and Viapiano MS: The proteoglycan brevican binds to fibronectin after proteolytic cleavage and promotes glioma cell motility. J Biol Chem 283: 24848-24859, 2008

27. Darnton SJ, Hardie LJ, Muc RS, Wild CP and Casson AG: Tissue inhibitor of metalloproteinase-3 (TIMP-3) gene is methylated in the development of esophageal adenocarcinoma: Loss of expression correlates with poor prognosis. Int J Cancer 115: 351-358, 2005

28. Hashimoto G, Shimoda M and Okada Y: ADAMTS-4 (aggrecanase-1) interaction with the C-terminal domain of fibronectin inhibits proteolysis of aggrecan. J Biol Chem 279: 32483-32491, 2004.

29. Miyazaki T, Kato H, Nakajima M, Faried A, Takita J, Sohda M, Fukai Y, Yamaguchi S, Masuda N, Manda R, Fukuchi M, Ojima H, Tsukada K and Kuwano H: An immunohistochemical study of TIMP-3 expression in oesophageal squamous cell carcinoma. Br J Cancer 91: 1556-1560, 2004.

30. Ryder SD: Guidelines for the diagnosis and treatment of hepatocellular carcinoma (HCC) in adults. Gut 52: iii1-iii8, 2003.

31. Berasain C, Castillo J, Prieto J and Avila MA: New molecular targets for hepatocellular carcinoma: the ErbB1 signaling system. Liver Int 153: 174-185, 2007.

32. Zimmers TA, McKillop IH, Pierce RH, Yoo J and Koniaris LG: Massive liver growth in mice induced by systemic interleukin 6 administration. Hepatology 38: 326-334, 2003.

33. Masui T, Hosotani R, Tsuji S, Miyamtot Y, Yasuda S, Ida J, Nakajima S, Kawaguchi M, Koybayashi H, Koizuma M, Toyoda E, Tulachan S, Arii S, Doi R and Imamura M: Expression of METH-1 and METH-2 in pancreatic cancer. Clin Cancer Res 7: 3437-3443, 2001. 